\title{
Ziffern und Buchstaben
}

Römische Ziffern kennzeichnen die verschiedenen Bedeutungen eines Wortes

Arabische Ziffern

ohne Punkt: kennzeichnen den Typ der Flexion, vgl. S. XVff., S. XXIf.

mit Klammer: kennzeichnen verschiedene Gliederungen in der Bedeutungsbeschreibung

Mit hochgestellten kleinen arabischen Ziffern werden Homonyme gekennzeichnet

Mit kleinen lateinischen Buchstaben wird der Akzenttyp der Substantive gekennzeichnet, vgl. S. XIV

\section{Lateinische Schrift}

\section{Schriftarten}

In Normalschrift stehen die Wortbedeutungen

In kursiver Schrift stehen die grammatischen Angaben sowie Erklärungen zur Bedeutung und Anwendung der Wörter

In kleiner Schrift stehen Ergănzungen zur Wortbedeutung, die besonders auf die Anwendungen im Redezusammenhang hinweisen

Kyrillische Schrift

In gesperrter Schrift stehen die Aspektentsprechungen der Verben

In kursiver Schrift stehen Angaben über die Aussprache des russischen Wortes

\section{Aussprache und Schrelbung der russischen Wörter}

Abweichungen von den Regeln der Aussprache werden in-eckigen Klammern hinter dem Stichwort genannt, und zwar nur für den betreffenden Teil des Wortes, z. B. naprép [ $m$ s]. In diesen Ausspracheangaben werden die russischen Buchstaben in ihrem gewöhnlichen Lautwert angewandt, z. B. bedeutet оте́ль $[m \vartheta]$, daB das $t$ hart, nicht weich gesprochen wird. Der Buchstabe $h$ in den Ausspracheangaben bedeutet die stimmhafte Entsprechung des russ. $x$.

Der Vokal der betonten Silbe ist regelmåBig mit dem Akzentzeichen versehen. Zwei Akzentzeichen in einem Wort bedeuten, daB beide Betonungen vorkommen.

Mit kleinen Buchstaben geschriebene Abkürzungswörter werden entsprechend dem

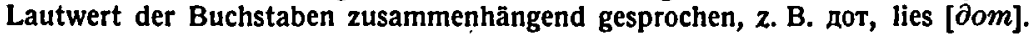

Mit großen Buchstaben geschriebene Abkürzungswörter werden entsprechend dem Lautwert der Buchstaben zusammenhăngend gesprochen, wenn Genus- und Deklinationsangaben stëhen, z. B.TACC 2, lies [mac]; fehlen solche Angaben, so werden diese Abkürzungswörter entsprechend der russischen Benennung der Buchstaben (vgl. S. XI) buchstabiert, also jeder Buchstabe als eine Silbe gesprochen, z. B. MTC, lies [จ.ณməsc].

Großer Anfangsbuchstabe steht im Wörterbuch nur in solchen russ. Wörtern, die diesen auch außerhalb des Satzanfanges verlangen; die auch im Russischen obligatorische Schreibung großer Anfangsbuchstaben nach jedem SatzschluB wird also der Deutlichkeit wegen im Wörterbuch nicht befolgt. 